\title{
A NEW RECORD OF YELLOWMARGIN TRIGGERFISH (Pseudobalistes flavimarginatus) (TETRAODONTIFORMES: BALISTIDAE) FROM THE BAY OF BENGAL OF BANGLADESH PROXIMITY
}

\author{
Alam, M. M., S. Sultana and M. N. Naser ${ }^{1}$ \\ Marine Fisheries Department, Marine Fisheries Academy, Fish Harbor, Chittagong 4000, Bangladesh; \\ ${ }^{1}$ Department of Zoology, University of Dhaka, Dhaka 1000, Bangladesh
}

\begin{abstract}
Pseudobalistes flavimarginatus (Ruppell, 1829) is a triggerfish species belonging to the Family Balistidae under the Order Tetraodontiformes. It was reported at the very first time from the region proximal to the south patches fishing ground of the Bay of Bengal (Bangladesh). The fish is known as Yellowmargin triggerfish due to the presence of body colour, yellow and gray. The total length of the voucher fish is $39.95 \mathrm{~cm}$ (Standard length $32.5 \mathrm{~cm}$ ) and $1540 \mathrm{~g}$ by weight. It has a deep, moderately compressed body with inconspicuous lateral lines, encased in very thick and hard skin with large boney scales (except rostral region). The fish body bears two dorsal fins with three visible spines. Dorsal, anal and pectoral-fin rays are soft and branched. The taxonomic formula for the species is D III/27; A 0/25; P 15; V I/7; C 15; Lt. 35-36. Gill openings are moderately short, vertical to oblique slit in front of pectoral-fin base. Concerning distribution, the species is not reported before in Bangladesh and not even recorded from other maritime Bay of Bengal localities of Eastern India and Sri Lanka; whereas it was already reported in other bio-geographical regions (detailed in article). The voucher specimen is preserved at the Marine Fisheries Academy Museum, Bangladesh for further reference use.
\end{abstract}

Key words: Balistidae, Yellowmargin Triggerfish, Pseudobalistes flavimarginatus, South Patches, Bangladesh.

\section{INTRODUCTION}

There are twelve genera of balistid fishes recorded in marine or estuarine water from $34^{\circ} \mathrm{N}-34^{\circ} \mathrm{S}$, and $27^{\circ} \mathrm{E}-124^{\circ} \mathrm{W}$, ranging from the Red Sea south to Natal, South Africa and east through Indonesia to the Tuamoto Islands, north to southern Japan, Maldives and north-western Western Australia, the northern Great Barrier Reef, Queensland to the central coast of New South Wales, Philippines and Indian-Pacific Ocean (except the Hawaiian Islands) (Nelsen et al. 2016). The fish inhabits solitarily or in pairs in saltwater-brackish and reef-associated marine environment, lagoon slope and floor, often in silt habitats at the depth range $(2-50 \mathrm{~m})$ of the zone (Froese and Pauly 2005). Youngs are found in small aggregations. Adults are usually seen solitary, except in pairs while nesting and males congregate on certain sand flats adjacent to reefs. They are rare to catch in low abundance. Yellowmargin triggerfish can grow to a maximum length of $60 \mathrm{~cm}$. The fish feed on tips of coral branches, gastropods, crustaceans, foraminiferans, tunicates and also on sea urchins. They are marketed either fresh or dried-salted for food, but potentially hazardous in some areas due to ciguatera poisoning for human.

Apart from its known geographical distribution, a specimen of Pseudobalistes flavimarginatus was collected by a commercial trawler from the Bay of Bengal. The aim of the present study envisages validating the identification and describing the voucher specimen of the species for the inclusion into fish database, which would be a very first new record from the Bay of Bengal region of Bangladesh.

\section{MATERIAL AND METHODS}

The specimen was collected from a deep sea trawler while fishing at the south of south patches, west of the Saint Martin's island of the Bay of Bengal. Collected specimen was then handed to the Marine Fisheries Academy, Chittagong, Bangladesh as unknown species by the fishers. External features of the fish were studied following the classical literature of Fischer and Bianchi (1984). The morphometric 
data were recorded according to Matsuura (1980, 2009). Examination of the nasal apertures, counts of fin spines, rays and lateral lines, arrangement and morphology of the scales on the cheek, body, abdomen, caudal peduncle were made carefully. Body colour and pigmentation of the specimen were examined and recorded. Adequate photographs were taken to support the interpretation of the morphological designation. Literatures from Fischer and Bianchi (1984), Froese and Pauly (2005) and Sahayak et al. (2014) were consulted and followed for taxonomic identification.

\section{Morphometry}

\section{RESULTS AND DISCUSSION}

The total length of the fish was $39.95 \mathrm{~cm}$, standard length $32.5 \mathrm{~cm}$, head length $10.5 \mathrm{~cm}$, length of the superior jaw $2.75 \mathrm{~cm}$, first dorsal fin basis length $6.50 \mathrm{~cm}$, second dorsal fin basis length $11.7 \mathrm{~cm}$, maximum body height $19 \mathrm{~cm}$, height of anterior part of first dorsal fin $6 \mathrm{~cm}$, height of anterior part of second dorsal fin $5 \mathrm{~cm}$, height of caudal peduncle $2.4 \mathrm{~cm}$, head curvature length $6.5 \mathrm{~cm}$, length of post head curvature $6.5 \mathrm{~cm}$, length of caudal fin $7.5 \mathrm{~cm}$ and the body weight $1540 \mathrm{~g}$. Different morphological characteristics of the fish are presented in Fig.1 and Table 1.

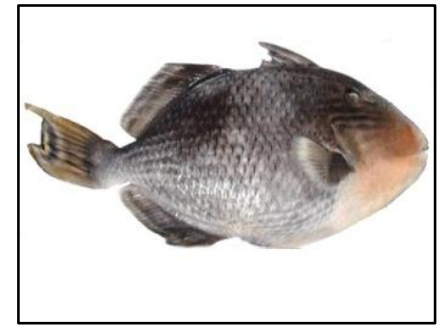

$\mathrm{a}$

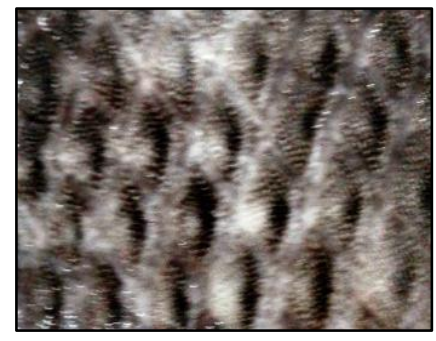

e

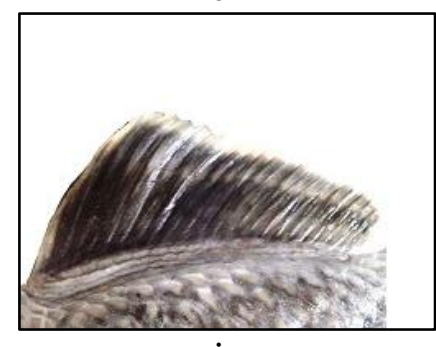

$\mathrm{i}$

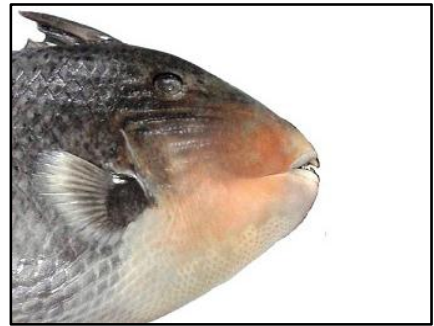

b

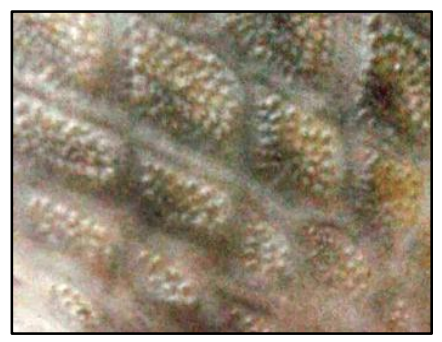

$\mathrm{f}$

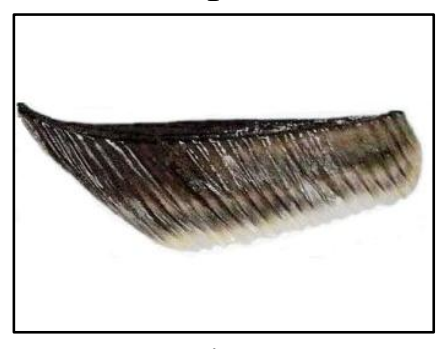

j

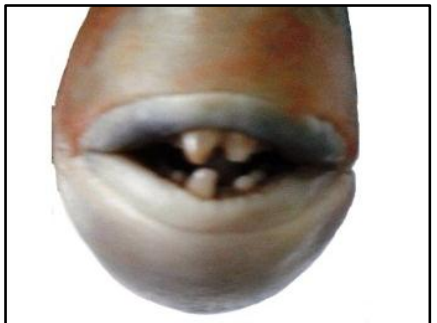

$\mathrm{c}$

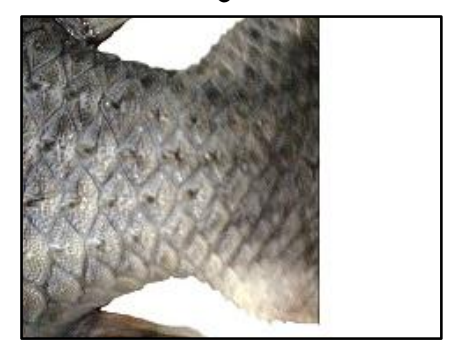

g

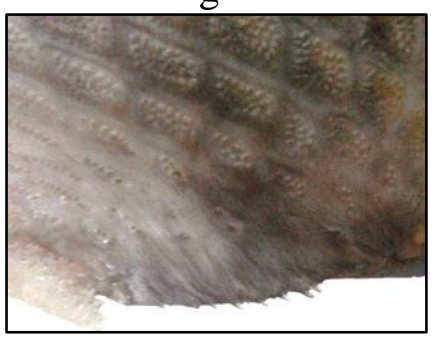

k

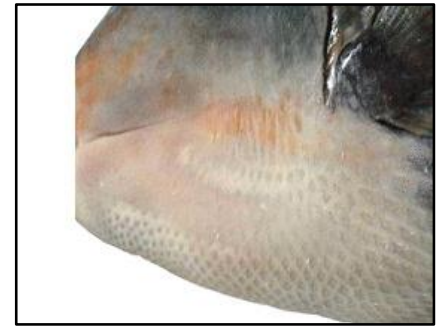

d

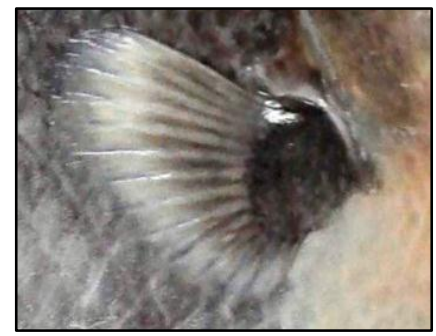

$\mathrm{h}$

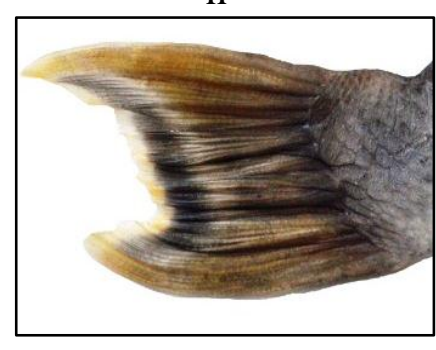

1

Fig. 1. Morphological characteristics of Yellow margin Triggerfish (Pseudobalistes flavimarginatus): a. External features, b. Lateral view of mouth, c. Frontal view of mouth d. Scales of cheek, e. Scales of dorsal side, f. Scales of ventral side, g. Spines caudal peduncle, h. Pectoral fin with gill opening, i. Dorsal fin, j. Anal fin, k. Pelvic fin, 1. Caudal fin. 
Table 1. Morphological characteristics of Yellowmargin Triggerfish Pseudobalistes flavimarginatus from Bangladesh.

\begin{tabular}{ll}
\hline Feature & Characteristics \\
\hline Body & Body deep, moderately compressed, encased in very thick and tough skin. Body color gray, throat \\
& yellow. Rostral region not covered with scales. Lateral line inconspicuous. \\
Mouth & Mouth small and terminal. Hard jaws. \\
Teeth & Teeth white, uneven, serrated, strong and separate, eight in the outer series of both jaws. \\
Scales & Relatively large and hard scales, easily discernible as individual units. Small spines are present on the \\
Gill opening & scales of caudal peduncle. \\
Fins & Gill opening, a moderately short, vertical to oblique slit in front of pectoral-fin base. \\
& Outer edge of dorsal fin is yellow. Two dorsal fins, first dorsal fin with three visible spines, the \\
& second spine more than 1/2 length of first spine; first spine capable of being locked in an erect position \\
& by second spine \\
& Outer edge of anal fin is also yellow. Second dorsal and anal fin similar in shape \\
& Pelvic fins rudimentary. An encasing scales present at end of pelvious. \\
& Caudal fin homocercal with double indentation. Caudal fin almost yellow coloured with black \\
& patches.
\end{tabular}

\section{Taxonomic identification}

The key to the identification of the species is as follows-

* Fish composed of true bones. Scales modified into minute sharp granules, needle like spines, and fused in a case........................................................ Order: Trtradontoformes ${ }^{* 1}$

${ }^{*}$ Body laterally compressed, usually fairly deep, scales modified and spinous ......................................................................... Sub order: Balistoidei ${ }^{2}$

${ }^{*}$ Fin spines mostly rudimentary, dorsal with 1-3 spines, the first largest and often with locking mechanism. ...........................................................Family: Balistidae ${ }^{3}$

${ }^{3}$ Gill opening, a moderately short, vertical to oblique slit in front of pectoral-fin base...........................................................Genus: Pseudobalistes ${ }^{4}$

${ }^{4}$ Cheeks without scale or naked, with separate scales elevated rows in caudal pednacle................................................... flavimarginatus

These taxonomic characteristics are confirmed by Munro (1955), Fischer and Bianchi (1984), Froese and Pauly (2005) and Sahayak et al. (2014). And we then considered the species as Pseudobalistes flavimarginatus.

\section{Taxonomic formula}

D III/27; A 0/25; P 15; V I/7; C 15; Lt. 35-36

\section{Biogeographical significance}

Fishes of the family Balistidae do not form a major fishery anywhere in Bangladesh and were not used before for human consumption. No significant research effort has been paid to any aspect of these fishes (Randall 1992). In worldwide, Balistid fishes are represented by twelve recorded genera (Matsuura 1980, 2009, Nelsen et al. 2016). It has to be noted that out of three genera, viz. Balistoides, Pseudobalistes and Parabalistes, two genera Pseudobalistes and Parabalistes showed similarities in many characters; and several authors made confused descriptions resulting improper identification or/and lack complete examination in nomenclature issues. The genus Pseudobalistes designated by Bleeker with the species, Pseudobalistes viridescensas (Bleeker, 1866) has been validated and named later as Balistoides (Fraser-Brunner, 1935), another genus being Parabalistes (Bleeker, 1866). 
There are 18 fish species form 11 genera of the family Balistidae recorded from western Indian ocean area no. 51 (Fischer and Bianchi 1984). But no record was made from the eastern part of the Bay of Bengal of India. Following previous record, the fishes of Balistidae family found in the Bay of Bengal, Bangladesh; viz. Abalis stellaris and Sufflamen capistratus (Hussain 1970, Quddus and Shafi 1983). However, Munro (1955) did not report any fish species in his vast work in Sri Lanka. Even Rajasuria (2014) did not report the species from the reef fishes of Sri Lanka. Randall (1992) and MRS (1997) recorded the fish from Maldives coral island from Indian Ocean. This fish was reported by the Scaps and Scott in 2014 while diving at Koh Tao coral reef, Gulf of Thailand. But it was reported earlier that they are not common in the area (Satapoomin 2000). The present investigation reports that the fish P. flavimarginatus (Ruppell, 1829) has been found first time from this part of the Bay of Bengal in the year 2016-2017 from Bangladesh region. The fish was only found before in Minicoy, Agatti, Tuticorin and Andaman islands in India (Rao 2010 and Sahayak et al. 2014).

For taxonomic identification, some of the distinctive characters of the collected specimen were used to identify at species level; body deep, moderately compressed, encased in very thick and tough skin; Body color is gray, throat yellow. Rostral region is not covered with scales. Lateral line is inconspicuous. Two dorsal fins present, first dorsal fin with three visible spines, the second spine more than 1/2 length of first spine; first spine capable of being locked in an erect position by second spine. Dorsal, anal and pectoral-fin rays are soft and branched. Gill opening is a moderately short, vertical to oblique slit in front of pectoral-fin base. The characters were thoroughly examined and recorded; and these were compared by consulting the above mentioned literatures to confirm the species. And that is why morphometric studies were given priority.

It can be said that the Pseudobalistes flavimarginatus is a valid species under the family Balistidae and recorded at the very first time in Bangladesh marine territory. Further efforts should be attempted to conserve the fish in the coral island areas. As the Andaman island sample was collected long time back by Dr Francis Day (Sahayak et al. 2014), the collection is made from the Bay of Bengal or the Andaman sea is not clearly described. Biogeographically the report of this fish P. flavimarginatus (Ruppell, 1829) is important as it is recorded first time from the south of south patches fishing grounds of the Bay of Bengal in Bangladesh territory. The record and the report will open an access to do further research on zoogeographical aspects of the species in future.

\section{ACKNOWLEDGEMENTS}

The Department of Marine Fisheries and Marine Fisheries Academy of Chittagong are cordially acknowledged by the authors for supplying the fish specimen. Heartfelt thanks are also offered to Mr. M. M. Shahiduzzaman, Head Assistant and Mr. Sujan Chakraborty, Laboratory Assistant, Marine Fisheries Academy of Chittagong, Bangladesh for their kind help during this work.

\section{REFERENCES}

Fischer, R. W. and G. Bianchi. 1984. FAO species identification sheets for fishery purposes: Area 51, Western Indian Ocean. Food and Agriculture Organization of the United Nations (FAO), Rome, Italy.

Froese, R. and D. Pauly. 2005. Pseudobalistes flavimarginatus. FishBase. www.fishbase.org.

Hussain, M. M. 1970. Marine and estuarine fishes of the North-East part of Bay of Bengal. Scientific Researches, East Regional Laboratories, Dhaka. VII(1): 1-502. 
Matsuura, K. 2009. Species accounts of Scatophagidae, Triacanthidae, Balistidae, Monacanthidae, Pstracidae, Tetradontidae, Diodontidae. In: S. Kimura, S.U. Satapoomin and K. Matsuura (eds.). Fishes of Andaman Sea, west coast of southern Thailand. National Museum of Nature and Science, Tokyo, Japan. 346 pp.

Matsuura, K., 1980. A revision of Japanese Balistoides fishes. I. Family Blastidae. Bull. Natl. Sci. Mus. Ser. A. (Zool.). 6(1): 27-69.

MRS. 1997. Fishes of the Maldives. Marine Research Section, Mins. of Fisheries and Agric. Rep. of Maldives. 408pp.

Munro, I. S. R. 1955. The Marine and Fresh water fishes of Ceylon. Ministry of External Affairs, Canberra, Australia. 349pp.

Nelsen, J. S., T. C. Grande and M. V. H. Wilson. 2016. Fishes of the world. John Wiley and Sons, Inc, NJ, USA. 707 pp.

Quddus, M. M. A and M. Shafi. 1983. Fisheries Resources of the Bay of Bengal. $1^{\text {st }}$ ed. Bangla Academy, Dhaka, pp. 424-426.

Rajasuriya, A. 2014. Field Guide to Reef Fishes of Sri Lanka. Vol. 2. IUCN, Colombo, Sri Lanka. 101 pp.

Randall, J. E. 1992. Divers guide to fishes of Maldives. IMMEL publishing, London, UK. 193 pp.

Rao, D.V. 2010. Field guide to corals and coral associated of Andaman and Nicobar islands. Zoological Survey India, Kolkata, India. 283pp.

Sahayak, S., K. K. Joshi and V. S. Murty. 2014. Taxonomic review of the genera Balistoides, Pseudobalistes and Parabalistes of the family Balistidae with redescription of species occurring in Indian seas. Indian J. Fish. 61(2): 19-27.

Satapoomin, U. 2000. A preliminary checklist of coral reef fishes of the gulf of Thailand, South China Sea. Raffles Bull. Zool. 48(1): 31-53.

Scaps, P. and C. Scott. 2014. An update to the list of coral reef fishes from Koh Tao, Gulf of Thailand. Checklist. 10(5): 1123-1133. 
J. biodivers. conserv. bioresour. manag. 3(2), 2017 